\title{
A Zn(II)-Based Sq1 Type 2D Coordination Polymer as a Highly Sensitive and Selective Turn-On Fluorescent Probe for $\mathrm{Al}^{3+}$
}

\author{
Dmitry I. Pavlov (D), Alexey A. Ryadun and Andrei S. Potapov *
}

Citation: Pavlov, D.I.; Ryadun, A.A.; Potapov, A.S. A Zn(II)-Based Sql Type 2D Coordination Polymer as a Highly Sensitive and Selective Turn-On Fluorescent Probe for $\mathrm{Al}^{3+}$. Molecules 2021, 26, 7392. https://doi.org/ $10.3390 /$ molecules 26237392

Academic Editors: Boiko Cohen and Mario Gutiérrez

Received: 15 November 2021 Accepted: 3 December 2021 Published: 6 December 2021

Publisher's Note: MDPI stays neutral with regard to jurisdictional claims in published maps and institutional affiliations.

Copyright: (c) 2021 by the authors. Licensee MDPI, Basel, Switzerland. This article is an open access article distributed under the terms and conditions of the Creative Commons Attribution (CC BY) license (https:// creativecommons.org/licenses/by/ $4.0 /)$.
Nikolaev Institute of Inorganic Chemistry, Siberian Branch of the Russian Academy of Sciences, 3 Lavrentiev Ave., 630090 Novosibirsk, Russia; pavlov@niic.nsc.ru (D.I.P.); ryadunalexey@mail.ru (A.A.R.)

* Correspondence: potapov@niic.nsc.ru; Tel.: +7-(383)-330-94-90

\begin{abstract}
A luminescent coordination polymer with the overall formula $\left\{\left[\mathrm{Zn}\left(\operatorname{tr}_{2} \text { btd }\right)(b p d c)\right] \cdot D M F\right\}_{n}$ (where $\operatorname{tr}_{2}$ btd $=4,7-d i\left(1 H-1,2,4\right.$-triazol-1-yl)-2,1,3-benzothiadiazole; bpdc $=4,4^{\prime}$-biphenyldicarboxylate) was synthesized and characterized by single-crystal and powder X-ray diffraction, thermogravimetric, infrared spectroscopy, and elemental analyses. Luminescent properties of the obtained compound were studied in detail both in the solid state and as a suspension in N,N-dimethylacetamide (DMA). It was found that $\left\{\left[\mathrm{Zn}\left(\operatorname{tr}_{2} \mathrm{btd}\right)(\mathrm{bpdc})\right] \cdot \mathrm{DMF}\right\}_{\mathrm{n}}$ exhibits bright turquoise luminescence with excellent quantum efficiency and demonstrates turn-on fluorescence enhancement effect upon soaking in DMA $\mathrm{Al}^{3+}$ solution. Fluorescence titration experiments were carried out and the detection limit for $\mathrm{Al}^{3+}$ ions was calculated to be $120 \mathrm{nM}$, which is among the lowest reported values for similar materials. Moreover, compound demonstrated excellent selectivity and reusability, and the mechanism of the response is discussed. These results indicate that $\left\{\left[\mathrm{Zn}\left(\operatorname{tr}_{2} \mathrm{btd}\right)(\mathrm{bpdc})\right] \cdot \mathrm{DMF}\right\}_{\mathrm{n}}$ is a promising probe for sensitive fluorescent $\mathrm{Al}^{3+}$ detection.
\end{abstract}

Keywords: 2,1,3-benzothiadiazole; 1,2,4-triazole; crystal structure; luminescence; coordination polymer; metal-organic framework; aluminum detection; fluorescence enhancement

\section{Introduction}

Detection of metal cations is an important task in a broad range of human activities. Their presence can cause interferences in materials processing, pose an environmental threat and danger to the public health. It is well-known that lead, cadmium, and mercury are extremely toxic to organisms [1-3]. Although its effect is not as dramatic as in the case of lead, aluminum can and does present a concern regarding its influence on the human health [4]. Aluminum is a ubiquitous metal, encountered daily in foods, beverages (including drinking water), air-borne particulates and fumes, kitchenware, alloys, pharmaceuticals, vaccines [5]. Due to its wide spread throughout general population's lives, an extensive research into aluminum physicochemical characteristics in relation to its uptake, buildup, and systemic bioavailability has been carried out [6]. This metal was confirmed as potentially toxic to the skeletal and hematopoietic systems [7,8]. There is an ongoing dispute considering the role of aluminum in the development of several neurodegenerative diseases, such as Alzheimer's disease or Parkinson's disease [9]. Several reports have attempted to link aluminum content in drinking water with dementia. In the early 1990s the case has been made that the evidence is strong enough to imply that a significant cutting of aluminum exposure would significantly reduce the prevalence of Alzheimer's disease [6]. Current exposure rates may be as little as $0.03 \mu \mathrm{g} / \mathrm{kg} /$ day in clean environment to $233 \mu \mathrm{g} / \mathrm{kg} /$ day in polluted environment [8]. Although the particular effect of aluminum exposure on etiology of neurodegenerative diseases is still debated, most reviews agree on several points: (i) Aluminum is very prevalent in the environment and there is some level of human consumption; (ii) neurotoxicity of high aluminum levels is well established; (iii) there is repeated epidemiological correlation between ingested aluminum and inci- 
dence of Alzheimer's disease $[9,10]$. Thus, it is evident that aluminum exposure should be kept at minimum as its biological effects are not fully understood yet.

Recently, a significant effort has been put into developing alternative methods for the detection of aluminum species since traditional methods such as chromatography [11], potentiometric methods and voltammetry [12], atomic absorption spectrometry [13], atomic emission spectrometry [14] have the disadvantages of complexity, requirement for expensive equipment, and non-real-time detection. Fluorescent sensing overcomes these disadvantages by offering high sensitivity along with selectivity, ease of operation, real-time response, and possibility for naked-eye recognition of the analytical signal [4,15-19].

Metal-organic frameworks (MOFs) also known as porous coordination polymers (PCPs), are porous crystalline highly ordered solids constructed by bridging metal ions or metal clusters with polytopic organic ligands. Their potential applications include catalysis [20,21], separation, and storage of gas and liquid mixtures [22-25], chemical sensing [26]. Utilization of MOFs as fluorescent probes offers additional advantages, such as improved selectivity and sensitivity, and reusability. In the recent decade, a vast array of metal-organic framework materials capable of selectively detecting metal ions, small molecules, nitroaromatics, etc., were reported. However, most $\mathrm{Al}^{3+}$-sensitive MOFs demonstrate luminescence quenching response [27-29]. To the best of our knowledge, "turn-on" selective MOF sensors for $\mathrm{Al}^{3+}$ are still a relatively rare occurrence [30,31].

Herein, preparation of a new 2,1,3-benzothiadiazole-based fluorescent coordination polymer $\left\{\left[\mathrm{Zn}\left(\operatorname{tr}_{2} \mathrm{btd}\right)(\mathrm{bpdc})\right] \cdot \mathrm{DMF}\right\}_{\mathrm{n}}(\mathbf{1})$, constructed using 4,7-di(1H-1,2,4-triazol-1-yl)-2,1,3benzothiadiazole ( $\operatorname{tr}_{2}$ btd, Figure 1$), 4,4^{\prime}$-biphenyldicarboxylic acid $\left(\mathrm{H}_{2} \mathrm{bpdc}\right.$, Figure 1$)$ as linker is reported. It was found that the coordination polymer $\mathbf{1}$ exhibits high selectivity and sensitivity toward $\mathrm{Al}^{3+}$ via a fluorescence enhancement (turn-on) effect. The determined detection limit of $\mathrm{Al}^{3+}$ ions of $120 \mathrm{nM}$ is among the best of the reported $\mathrm{Al}^{3+}$ MOF sensors.

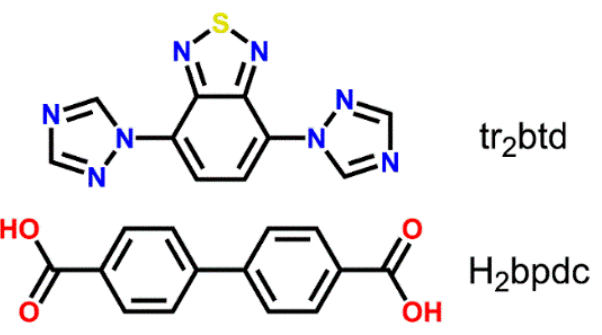

Figure 1. Organic linkers used in this study.

\section{Results and Discussion}

\subsection{Synthesis}

The $\operatorname{tr}_{2}$ btd ligand was synthesized in a moderate yield by the reaction of $\mathrm{Br}_{2}$ btd with $1 \mathrm{H}-1,2,4$-triazole in a superbasic medium $\mathrm{K}_{3} \mathrm{PO}_{4}-\mathrm{DMSO}$ (Scheme 1), the pure product was obtained by simple recrystallization, which presents an advantage compared to the previously reported method that requires column chromatography [32].

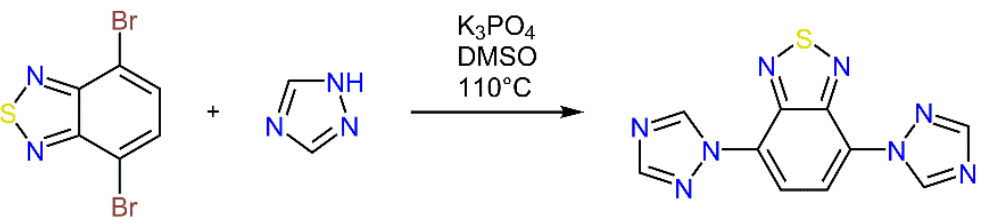

Scheme 1. Synthesis of the $\operatorname{tr}_{2}$ btd ligand.

Coordination polymer $\left\{\left[\mathrm{Zn}\left(\mathrm{tr}_{2} \mathrm{btd}\right)(\mathrm{bpdc})\right] \cdot \mathrm{DMF}\right\}_{\mathrm{n}}(\mathbf{1})$ was conveniently obtained in high yield by reacting $\operatorname{tr}_{2}$ btd, $\mathrm{H}_{2}$ bpdc and $\mathrm{Zn}\left(\mathrm{NO}_{3}\right)_{2} \cdot 6 \mathrm{H}_{2} \mathrm{O}$ in a mixed solvent system DMF:EtOH (3:1) at $100{ }^{\circ} \mathrm{C}$. 


\subsection{Structural Characterization}

Compound 1 crystallizes in a centrosymmetric monoclinic $\mathrm{P} 2{ }_{1} / \mathrm{c}$ space group. The asymmetric unit consists of three separate fragments. Each fragment includes a crystallographically independent zinc ion bonded by one dicarboxylate and one $\operatorname{tr}_{2}$ btd molecules (Figure 2). There are three DMF molecules per asymmetric unit, two of them participate in hydrogen bonding with 1,2,4-triazole rings (Figure S1), distance d(O16-C33) is $3.108 \AA$, and $\mathrm{d}(\mathrm{O} 4-\mathrm{C} 57)$ is $3.157 \AA$, while the other is disordered over two positions (occupancies 0.6 and 0.4 ). The coordination sphere of each $\mathrm{Zn}$ ion consists of four oxygen atoms from separate $b \mathrm{pdc}^{2-}$ anions and two nitrogen atoms from separate $\operatorname{tr}_{2} \mathrm{btd}$ molecules (Figure 2a). The distances $\mathrm{d}(\mathrm{Zn}-\mathrm{O})$ are in the range of 1.976(2)-2.0322(19) $\AA$ for the shorter bond and 2.3929(19)-2.633(3) $\AA$ for the longer bond. The distances $\mathrm{d}(\mathrm{Zn}-\mathrm{N})$ are in the range of 2.033(2)-2.099(2) $\AA$. The coordination polyhedra of $\mathrm{Zn}^{2+}$ ions can be treated as distorted octahedrons. Zinc cations are linked by $\operatorname{tr}_{2}$ btd molecules into polymeric chains which are cross-linked by bpdc ${ }^{2-}$ anions to form 2D layers. Three layers interpenetrate each other to form supramolecular sheets which are packed into stacks held together by weak $\pi-\pi$ interactions between $\operatorname{tr}_{2} b t d$ molecules and hydrogen bond between one of the bpdc ${ }^{2-}$ carboxylate oxygen atoms and 1,2,4-triazole ring (Figure S2). As a result of such stacking, channels propagating along the crystallographic axis $a$ are formed with the approximate size of $4 \times 8 \AA$. Free void volume of the structure calculated by PLATON software is $24 \%$. In the as-synthesized structure, these channels are partly occupied by DMF molecules, but are potentially capable of including other small molecules and/or ions upon activation. Topological analysis using ToposPro [33] suggests that coordination polymer $\mathbf{1}$ can be treated as 4-connected sql type uninodal net with point symbol $\left\{4^{4} \cdot 6^{2}\right\}$.
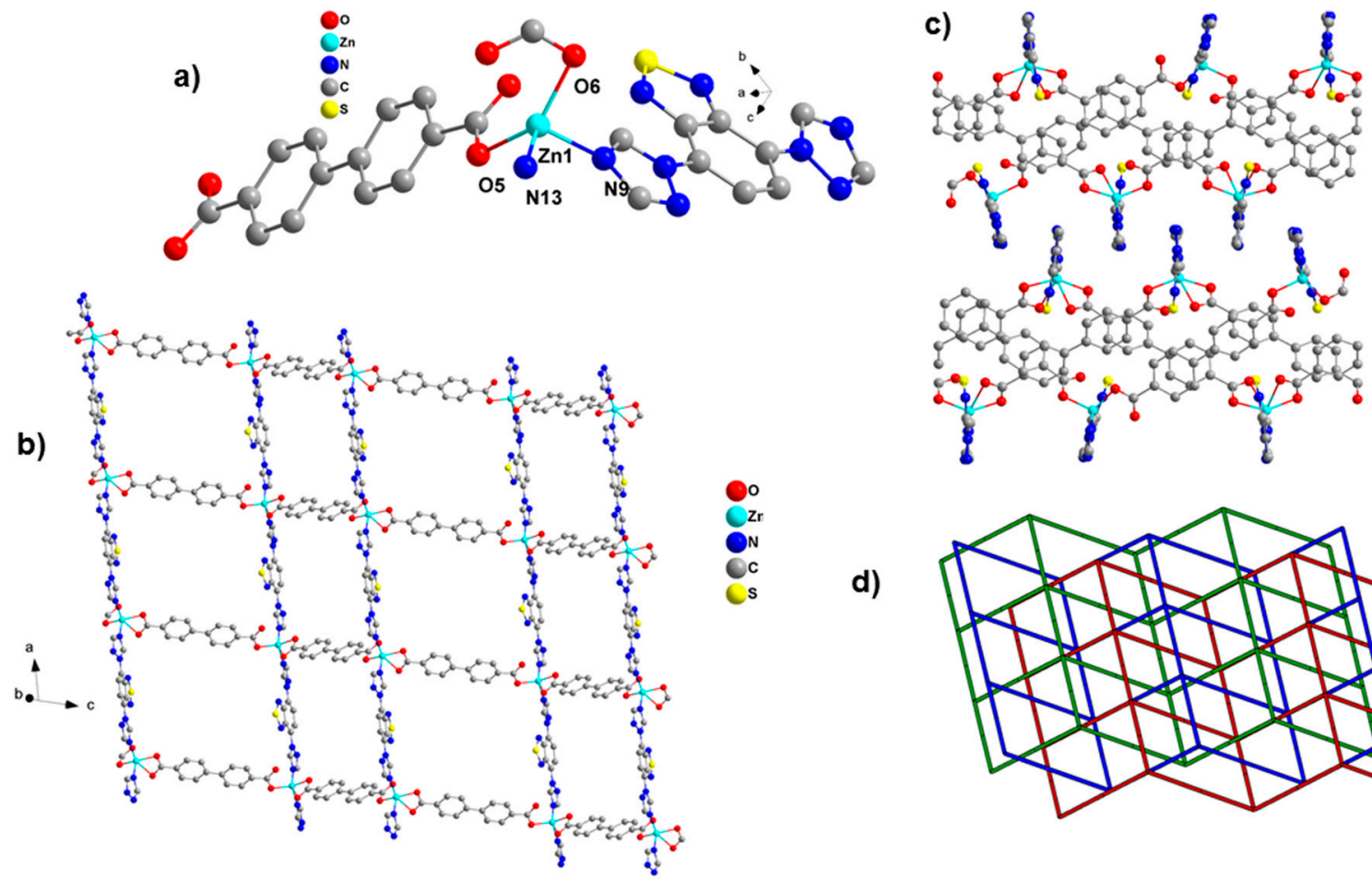

d)

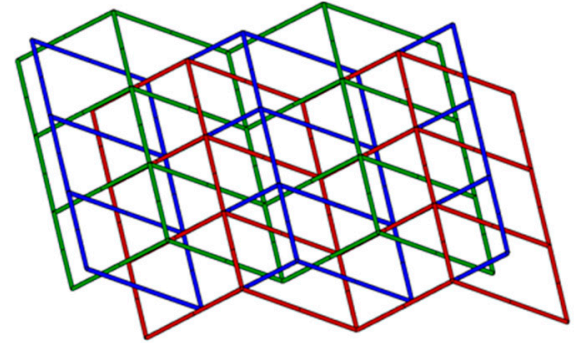

Figure 2. Crystal structure of the coordination polymer 1: (a) Structure of a typical building block; (b) 2D structure of a single layer of $\mathbf{1}$; (c) stacking of supramolecular layers, view along axis $a$; (d) topological representation of the structure as an interpenetrated net. 


\subsection{Powder X-ray Diffraction, IR Spectroscopy, and Thermal Behavior}

PXRD analysis was performed to confirm the phase purity of $\mathbf{1}$, its stability toward solvent, and metal inclusion. Comparison of the experimental and calculated diffraction patterns (Figure 3) confirms that the bulk product is a pure single phase, that is quite stable on prolonged exposure to moist air and DMA.

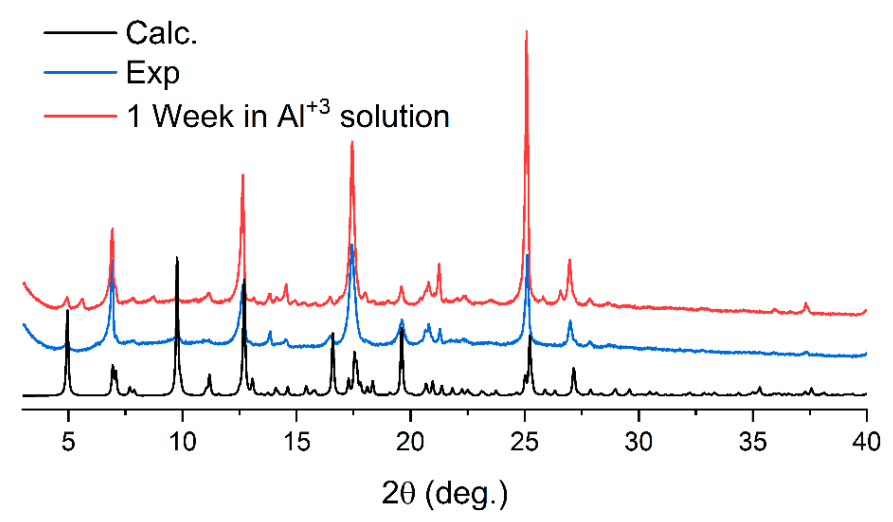

Figure 3. PXRD spectra of 1: experimental, calculated and after soaking for 1 week in $\mathrm{Al}^{3+}$ solution.

The thermal stability was investigated by means of thermogravimetric (TGA) analysis. The obtained TG curve suggests that $\mathbf{1}$ is thermally stable to approximately $320^{\circ} \mathrm{C}$. There is a clear step on the curve (Figure S3) that represents solvent loss (18\% observed mass loss, calculated $18.3 \%$ for three DMF, and $3.76 \mathrm{EtOH}$ molecules per elementary unit, which is consistent with elemental analysis and X-ray crystal structure data). Above $320^{\circ} \mathrm{C}$, degradation of the framework is clearly observed, which reaches completion at $730{ }^{\circ} \mathrm{C}$. Overall, coordination polymer 1 demonstrates a relatively good thermal stability.

The IR spectrum (Figure S4) contains several characteristic bands. Strong bands located at 1656 and $1386 \mathrm{~cm}^{-1}$ can be attributed to the asymmetric and symmetric carboxylate stretching vibrations. The separation between these bands $\Delta=270 \mathrm{~cm}^{-1}$ falls within the range of values usually observed for the asymmetric bidentate carboxylate coordination mode [34], which is consistent with the crystal structure data. Bands in the region of $1100-900 \mathrm{~cm}^{-1}$, along with a sharp band at $1527 \mathrm{~cm}^{-1}$ can be attributed to 1,2,4-triazole ring vibrations [35].

\subsection{Luminescent Properties}

Luminescent behavior of the coordination polymer 1 was studied both in the solid state and in DMA suspension. Compound 1 exhibits bright turquoise luminescence both in solid state and in DMA suspension. The emission maximum of $1\left(\lambda_{\mathrm{em}}=490 \mathrm{~nm}\right.$, $\lambda_{\mathrm{ex}}=375 \mathrm{~nm}$, Figure 4) is slightly blue-shifted compared to the free $\operatorname{tr}_{2}$ btd ligand $\left(\lambda_{\mathrm{em}}=510 \mathrm{~nm}, \lambda_{\mathrm{ex}}=375 \mathrm{~nm}\right.$, Figure S5), which indicates that not only $\operatorname{tr}_{2} \mathrm{btd}$, but also $\operatorname{bpdc}^{2-}$ ligand $\left(\lambda_{\mathrm{em}}=480 \mathrm{~nm}, \lambda_{\mathrm{ex}}=375 \mathrm{~nm}\right.$, Figure S6) are responsible for the luminescence of the framework. Moreover, there are three distinct bands in the excitation spectrum of 1 in DMA suspension, with the maxima located at $282 \mathrm{~nm}, 320 \mathrm{~nm}$, and $375 \mathrm{~nm}$ (Figure 4b), which further proves that both ligands participate in the excitation process. However, since there are no additional bands in the emission spectrum of $\mathbf{1}$ and in the excitation spectrum of the free ligand, a ligand-to-ligand charge transfer process can be assumed. Interestingly, a red shift could be noted when $\mathbf{1}$ is soaked in DMA, and emission maximum can be observed at $507 \mathrm{~nm}\left(\lambda_{\mathrm{ex}}=375 \mathrm{~nm}\right.$, Figure $\left.4 \mathrm{~b}\right)$. 

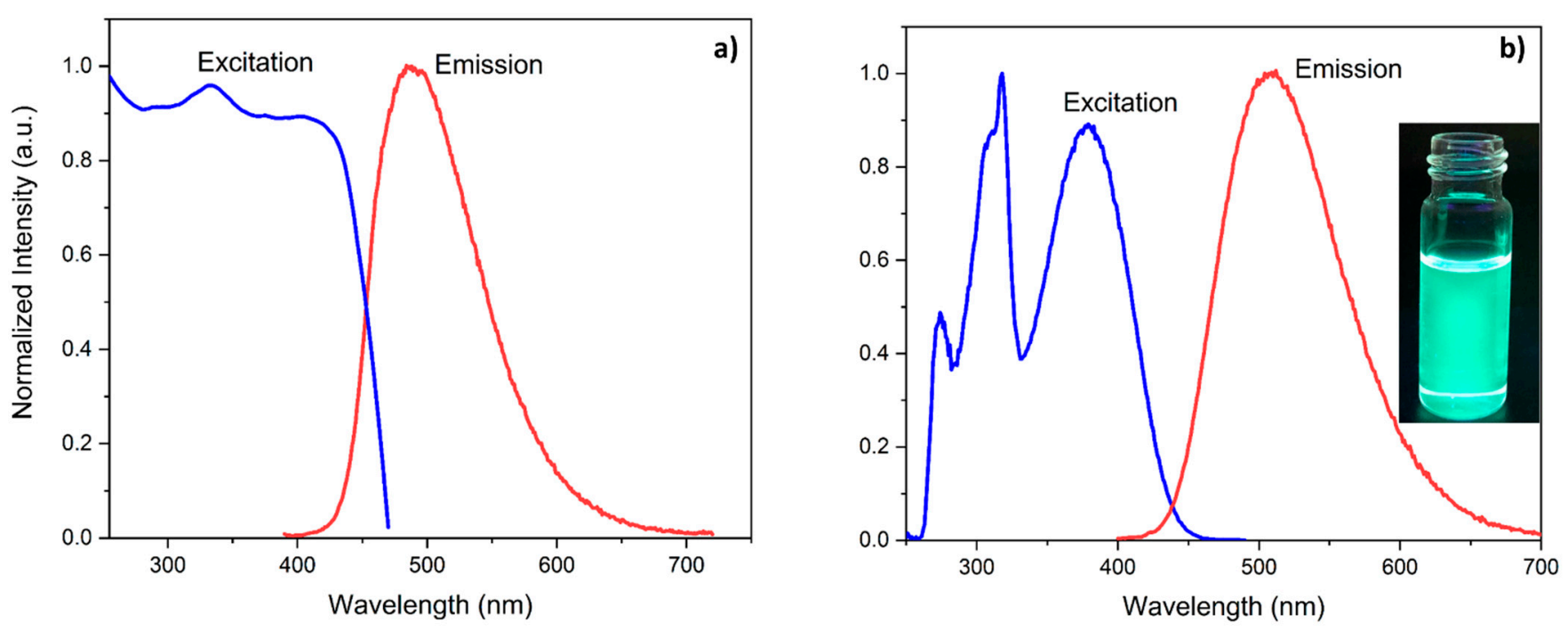

Figure 4. Excitation and emission spectra of 1: (a) In the solid state; (b) in DMA suspension. Inset: DMA suspension of 1 under 365 nm UV lamp.

\subsection{Metal Ion Sensing}

For the metal ion sensing experiments, DMA was chosen as a dispersion medium. For the screening test, metal salt solutions were added to the suspension to achieve concentrations of $0.01 \mathrm{mM}$. The results of the screening tests are shown in Figure 5a. It is quite obvious that the majority of metal ions $\mathrm{Zn}^{2+}, \mathrm{Cd}^{2+}, \mathrm{Ni}^{2+}, \mathrm{Co}^{2+}, \mathrm{Cu}^{2+}, \mathrm{Eu}^{3+}, \mathrm{La}^{3+}$, $\mathrm{Ba}^{2+}, \mathrm{Sr}^{2+}, \mathrm{Mg}^{2+}, \mathrm{K}^{+}, \mathrm{Na}^{+}, \mathrm{Pb}^{2+}$ ) had negligible quenching effect on the luminescence intensity. In case of $\mathrm{Cr}^{3+}$ and $\mathrm{Fe}^{3+}$ a slight (1.1 intensity of the blank sample) increase was observed. Aluminum undeniably stands out, as concentration of $0.01 \mathrm{mM}$ causes significant luminescence enhancement leading to a two-fold increase in the intensity (Figure 5a).

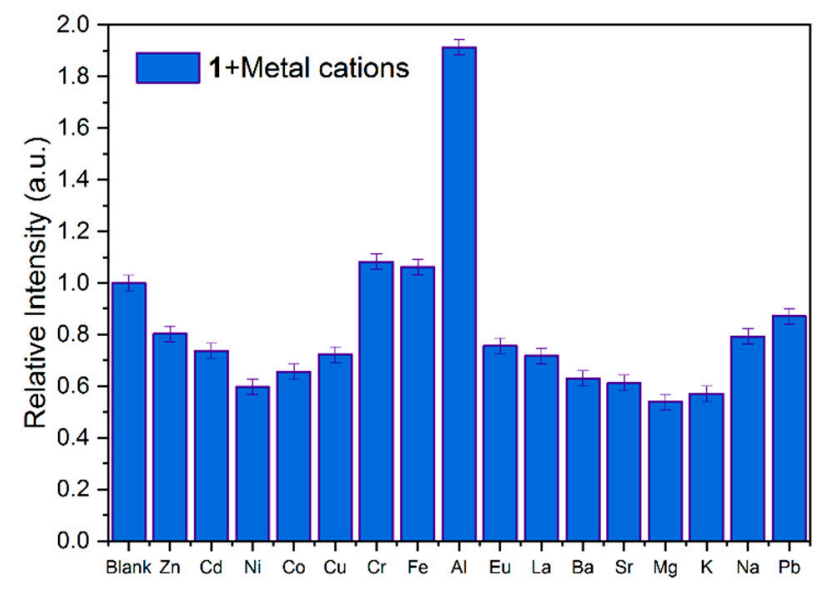

(a)

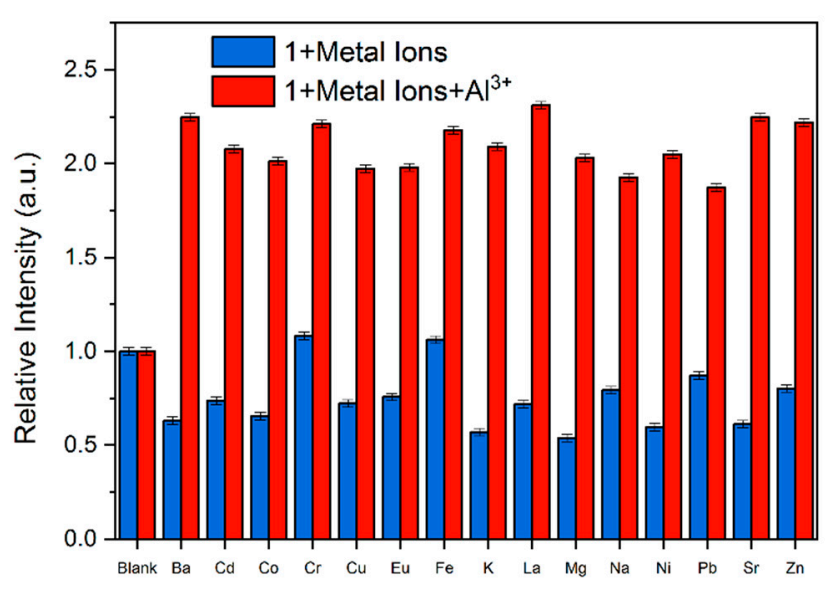

(b)

Figure 5. Luminescence intensity of the 1 suspension upon addition of metal ions. (a) $0.01 \mathrm{mM}$ of respective metal ion. (b) $0.01 \mathrm{mM}$ of $\mathrm{Al}^{3+}$ with 1 equivalent of other cations.

In addition, concurrent sensing experiments were performed, when equal concentrations of $\mathrm{Al}^{3+}$ and one of the other metal cations $\left(\mathrm{Zn}^{2+}, \mathrm{Cd}^{2+}, \mathrm{Ni}^{2+}, \mathrm{Co}^{2+}, \mathrm{Cu}^{2+}, \mathrm{Eu}^{3+}, \mathrm{La}^{3+}\right.$, $\mathrm{Ba}^{2+}, \mathrm{Sr}^{2+}, \mathrm{Mg}^{2+}, \mathrm{K}^{+}, \mathrm{Na}^{+}, \mathrm{Pb}^{2+}$ ) were introduced into the suspension. It was found that the presence of various cations did not interfere with the ability of $\mathbf{1}$ to detect aluminum, confirming the excellent selectivity of its luminescent response toward $\mathrm{Al}^{3+}$ ion (Figure $5 b$ ).

Photoluminescence quantum yields (QY) and luminescence lifetimes of the pristine suspension and suspension with $0.005 \mathrm{mM} \mathrm{Al}^{3+}$ were measured. The luminescence de- 
cay of 1 could be described by a two-exponential model with the lifetimes ( $4.8 \mathrm{~ns}$ and $16.6 \mathrm{~ns}$, Figure S7) characteristic for ligand-centered fluorescence. Upon addition of $\mathrm{Al}^{3+}$, the lifetimes did not change significantly (2.6 ns and $16.1 \mathrm{ns,} \mathrm{Figure} \mathrm{S8)} \mathrm{suggesting} \mathrm{a} \mathrm{static}$ fluorescence enhancement mechanism with the formation of an emissive complex in the ground state [36]. Upon addition of $\mathrm{Al}^{3+}$, a change in luminescence quantum yield from $24 \%$ to $40 \%$ was observed. To further explore the relationship between $\mathrm{Al}^{3+}$ concentration and luminescence properties of $\mathbf{1}$, fluorimetric titration experiments with increasing concentration of $\mathrm{Al}^{3+}$ in the suspension were carried out (Figure 6). Two linear regions (for concentration ranges $0.5-3 \mu \mathrm{M}$ and $4-8 \mu \mathrm{M}$ ) could be observed in the relationship between integrated fluorescence emission intensity ratios $\left(\mathrm{I} / \mathrm{I}_{0}\right)$ and $\mathrm{Al}^{3+}$ concentration (Figure $6 \mathrm{~b}$ and Figure S9). The detection limit was calculated from the lower concentration approximation using the well-established equation $3 \sigma / \mathrm{k}$ (where $\sigma$ is standard deviation calculated from 5 blank measurements and $\mathrm{k}$ is slope of the graph) [37] to be $120 \mathrm{nM}$. This value is among the best reported Al-sensing MOF materials (Table 1). These results indicate that 1 can be used as an effective, sensitive, and selective fluorescent probe for $\mathrm{Al}^{3+}$.

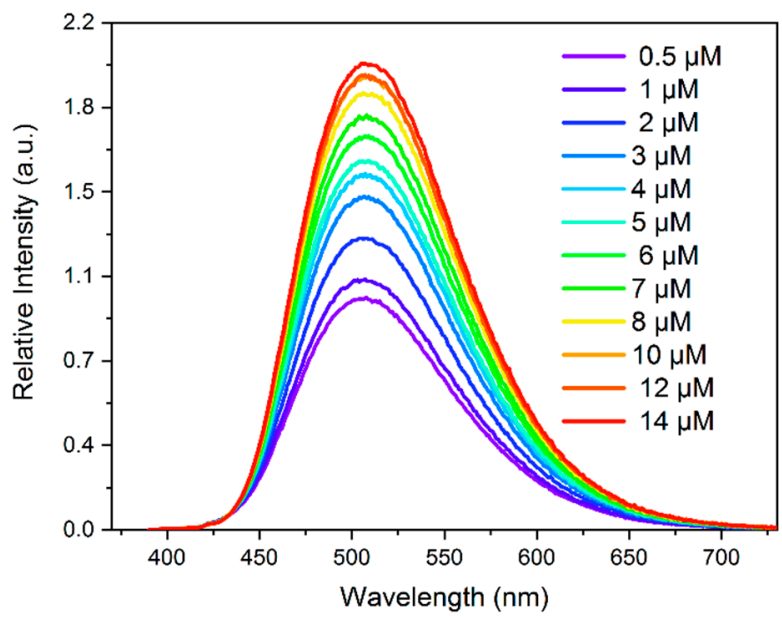

(a)

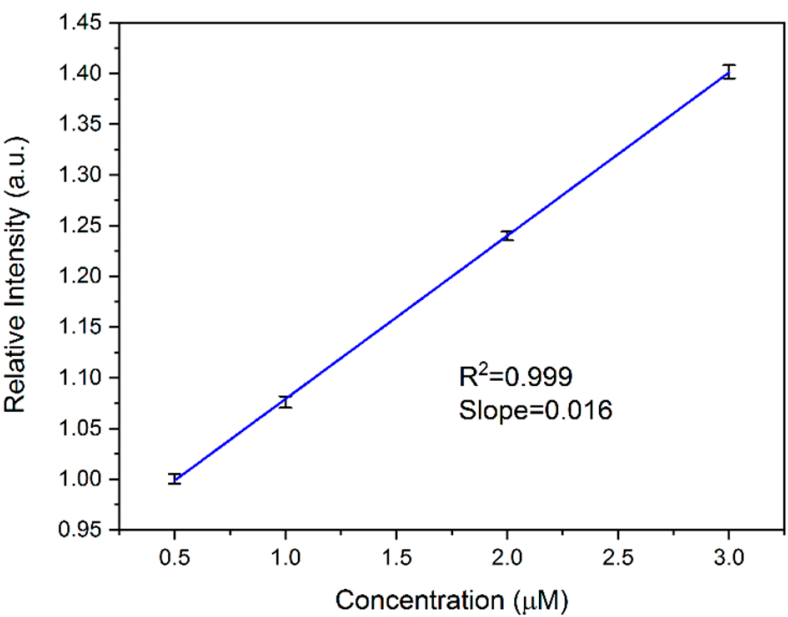

(b)

Figure 6. Fluorimetric titration spectra (a) and integrated relative intensity-concentration correlation in the linearity region (b). Spectrum for each concentration is an average of three measurements, error bars are mean \pm 1 SD.

Table 1. Characteristics of the coordination polymers sensitive to $\mathrm{Al}^{3+}$.

\begin{tabular}{|c|c|c|c|c|}
\hline Compound Name & Detection Limit & $\begin{array}{c}\text { Mechanism } \\
\text { and Selectivity }\end{array}$ & $\begin{array}{l}\text { Detection } \\
\text { Medium }\end{array}$ & Reference \\
\hline$\left\{\left[\mathrm{Zn}\left(\operatorname{tr}_{2} \mathrm{btd}\right)(\mathrm{bpdc})\right] \cdot \mathrm{DMF}\right\}_{\mathrm{n}}$ & $120 \mathrm{nM}$ & $\begin{array}{l}\text { turn-on } \\
\text { selective }\end{array}$ & DMA & This work \\
\hline$\left[\mathrm{Cd}(\text { Hcip })(\text { bpea })_{0.5}\left(\mathrm{H}_{2} \mathrm{O}\right)\right]_{\mathrm{n}}$ & $1.31 \mu \mathrm{M}$ & $\begin{array}{c}\text { turn-on } \\
\text { not selective }\end{array}$ & DMF & [38] \\
\hline$\left\{\left[\mathrm{Tb}(\mathrm{HCpIDC})\left(\mathrm{H}_{2} \mathrm{O}\right)_{2}\right] \cdot 2 \mathrm{H}_{2} \mathrm{O}\right\}_{\mathrm{n}}$ & $50 \mathrm{nM}$ & $\begin{array}{l}\text { turn-on } \\
\text { not selective }\end{array}$ & Water & [39] \\
\hline$\left[\mathrm{Cd}\left(\mathrm{H}_{2} \mathrm{dhbdc}\right)(\mathrm{NI}-\mathrm{mbpy}-34)_{2}\right]_{\mathrm{n}}$ & $340 \mathrm{nM}$ & $\begin{array}{c}\text { Turn-on } \\
\text { not selective }\end{array}$ & Water & [40] \\
\hline$[\mathrm{Zn}(\mathrm{DMA})(\mathrm{TBA})]_{\mathrm{n}}$ & $1.97 \mu \mathrm{M}$ & $\begin{array}{l}\text { turn-on } \\
\text { not selective }\end{array}$ & Water & [41] \\
\hline$\left\{[\mathrm{Co}(\mathrm{TPB})(\mathrm{BDC})] \cdot 0.5 \mathrm{H}_{2} \mathrm{O}\right\}$ & - & $\begin{array}{c}\text { turn-on } \\
\text { not selective }\end{array}$ & Water & [42] \\
\hline
\end{tabular}


Table 1. Cont.

\begin{tabular}{ccccc}
\hline Compound Name & Detection Limit & $\begin{array}{c}\text { Mechanism } \\
\text { and Selectivity }\end{array}$ & $\begin{array}{c}\text { Detection } \\
\text { Medium }\end{array}$ & Reference \\
\hline JXUST-2 & $100 \mathrm{nM}$ & $\begin{array}{c}\text { turn-on } \\
\text { not selective }\end{array}$ & DMA & [43] \\
\hline JXUST-3 & $55 \mathrm{nM}$ & $\begin{array}{c}\text { turn-off } \\
\text { not selective } \\
\text { JXUST-1 }\end{array}$ & EtOH & [44] \\
\hline selective & DMF & [45] \\
\hline
\end{tabular}

Reusability is an important factor in any practical application. To explore the possibility of using $\mathbf{1}$ for the detection of $\mathrm{Al}^{3+}$ several consecutive times, $\mathbf{1}$ was soaked in $\mathrm{Al}^{3+}$ solution, then the fluorescence spectrum was recorded, the framework was filtered out, washed with ethanol, and soaked again. We ran the sample through additional three cycles, and the results are shown in Figure S10. It is evident that both intensity and the luminescent response of $\mathbf{1}$ did not suffer significant change on repeated sensing experiments.

To demonstrate that 1 can be used for practical application in the detection of $\mathrm{Al}^{3+}$ ions, fluorescent paper strips were prepared by sonicating strips of filter paper in the DMA suspension of 1 . The paper was dipped in the $0.01 \mathrm{mM}$ solution of $\mathrm{Al}\left(\mathrm{NO}_{3}\right)_{3}$ in DMA. As it is evident from the photo (Figure 7), $\mathbf{1}$ can be used for the practical naked-eye detection of $\mathrm{Al}^{3+}$ present in the solution.

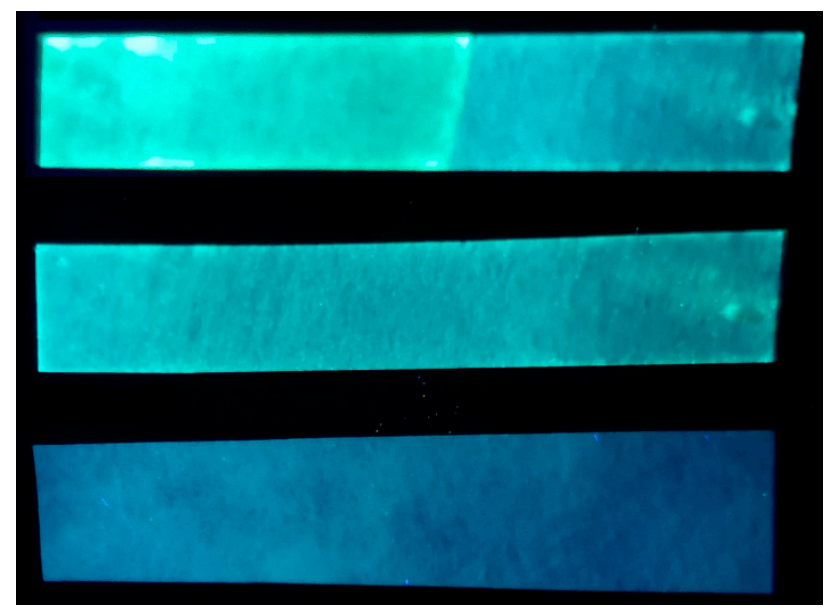

Figure 7. Photographs of filter paper strips under $365 \mathrm{~nm}$ UV light, bottom to top: untreated paper strip; paper strip treated with the suspension of $\mathbf{1}$; paper strip, one half of which (left) was dipped into $1 \mathrm{mM} \mathrm{Al}^{3+}$ solution.

To further explore the applicability of 1 for $\mathrm{Al}^{3+}$ determination in real samples, tap water was analyzed using the calibration regressions described above. For this, $100 \mathrm{~mL}$ of tap water was evaporated to dryness, $1 \mathrm{~mL}$ of DMA was stirred with the solid residue for $20 \mathrm{~min}$, the insoluble residue was filtered out, and $100 \mu \mathrm{L}$ of the filtered DMA were introduced to the 1 suspension. The emission spectra for the blank and tap water samples were recorded and compared, and $\mathrm{Al}^{3+}$ concentration in the tap water was calculated to be approximately $0.2 \mu \mathrm{M}$. To elucidate the possible influence of the analytical matrix (i.e., all other metal cations and anions present in the tap water), $120 \mu \mathrm{L}$ of $10^{-4} \mathrm{M} \mathrm{Al}^{3+}$ solution was added to both samples (total volume was $2 \mathrm{~mL}$ ). After leaving the samples to equilibrate for $30 \mathrm{~min}$, emission spectra were recorded again (Figure S11) and aluminum recovery between spiked real and blank samples was calculated to be $91 \%$. The experiment was repeated three times and the method precision (as relative standard deviation) was calculated to be $3.7 \%$ and an accuracy of $4.8 \%$ was achieved. 
To date, several possible mechanisms responsible for the luminescence enhancement upon guest inclusion into the coordination polymer were described: (i) Structural reorganization of the framework; (ii) exchange of metal cations; (iii) specific non-covalent interactions with the pore or channel surface. Possible structural changes were unequivocally ruled out, as PXRD pattern of $\mathbf{1}$ soaked in $\mathrm{Al}^{3+}$ solution is consistent with the as-synthesized and calculated patterns (Figure 3). As $\mathbf{1}$ is a neutral framework it is highly unlikely that any cation exchange takes place within the structure.

Time-dependent fluorescence measurements afford some insight into the mechanistic side of the observed phenomenon, as after the addition of $\mathrm{Al}^{3+}$ fluorescence intensity slowly rises, reaching a maximum after approximately $10 \mathrm{~min}$ (Figure S12). This may be due to kinetics of $\mathrm{Al}^{3+}$ ions permeation into the framework channels and windows. CIE chromaticity diagram reveals a slight change in luminescence color (Figure S13), which shifts into the green area of the spectrum, which can be a sign of $\mathrm{Al}^{3+}$ ions interacting with $\operatorname{tr}_{2} \mathrm{btd}$ molecules in the structure, hindering the mobility of the fragments, thus reducing the amount of energy released through non-radiative pathways. This leads to the increase of $\operatorname{tr}_{2}$ btd contribution in the emission of the framework, which results in intensity increase and slight color shift ( $\operatorname{tr}_{2} \mathrm{btd}$ emission maximum is located at $515 \mathrm{~nm}$ ). Aluminum nitrate in DMA (in the concentration range used in this study) does not show any absorption in the excitation region of 1 , thus energy transfer leading to luminescence quenching can be ruled out.

Overall, when compared to the other reported $\mathrm{Al}^{3+}$ sensitive coordination polymerbased materials (Table 1), 1 exhibits excellent performance with regard to sensitivity and selectivity and has a significant potential to be used as a fluorescent probe for $\mathrm{Al}^{3+}$.

\section{Materials and Methods}

All chemicals except for $\operatorname{tr}_{2}$ btd were purchased from commercial sources, were of at least analytical grade, and used without additional purification.

NMR spectra were recorded with a Bruker Advance III (500 MHz) instrument.

IR spectra in $\mathrm{KBr}$ pellets were recorded in the range $4000-400 \mathrm{~cm}^{-1}$ on a Bruker Scimitar FTS 2000 spectrometer.

Thermogravimetric analysis was done on a NETZSCH TG 209 F1 thermobalance in a stream of $\mathrm{He}$ in the range of 50 to $800^{\circ} \mathrm{C}$, heating rate $10^{\circ} \mathrm{C} / \mathrm{min}$.

Photoluminescence spectra and luminescence decay kinetics were recorded on Horiba Fluorolog 3 (HORIBA Jobin Yvon SAS, Edison, NJ, USA) equipped with 450W ozone-free Xe lamp (HORIBA Jobin Yvon SAS, Edison, NJ, USA), a cooled PC177CE-010 photon detection module (HORIBA Jobin Yvon SAS, Edison, NJ, USA) with R2658 photomultiplier, and double grating excitation and emission monochromators. Absolute quantum yields were determined using Quanta- $\phi$ integrating sphere (HORIBA Jobin Yvon SAS, Edison, NJ, USA). Excitation and emission spectra were corrected for source intensity (lamp and grating) and emission spectral response (detector and grating) by standard correction curves. For measurements powdered samples were placed between two non-fluorescent quartz plates. Photoluminescence measurements of DMA suspensions were carried out in $1 \mathrm{~cm}$ quartz cuvettes.

Powder X-ray diffraction (PXRD) analysis was performed at room temperature on a Shimadzu XRD-7000 diffractometer (Shimadzu Corporation, Kyoto, Japan, $\mathrm{Cu}-\mathrm{K} \alpha$ radiation, $\lambda=1.54178 \AA$ ).

Elemental analysis was carried out on a Vario Microcube analyzer (Elementar Analysensysteme $\mathrm{GmbH}$, Langenselbold, Germany).

\subsection{Synthesis of 4,7-di(1H-1,2,4-triazol-1-yl)-2,1,3-benzothiadiazole}

Anhydrous $\mathrm{K}_{3} \mathrm{PO}_{4}(3.61 \mathrm{~g}, 17 \mathrm{mmol})$ was suspended with $1 \mathrm{H}-1,2,4$-triazole $(1.17 \mathrm{~g}$, $17 \mathrm{mmol}$ ) in $50 \mathrm{~mL}$ of dimethyl sulfoxide and heated at $80{ }^{\circ} \mathrm{C}$ with stirring for $30 \mathrm{~min}$. 4,7Dibromobenzo-2,1,3-thiadiazole $(1.00 \mathrm{~g}, 3.4 \mathrm{mmol})$ was added and the mixture was stirred at $110^{\circ} \mathrm{C}$ for $24 \mathrm{~h}$. Then the mixture was poured on ice-water and filtered. Greenish- 
brown crude product was drier on air and pure product was obtained by recrystallization from DMF:EtOH (1:1) mixture. Bright-green needles were filtered from the red mother liquor and dried on air at $60{ }^{\circ} \mathrm{C}$. Yield $432 \mathrm{mg}(47 \%)$, green needles. ${ }^{1} \mathrm{HNMR}(500 \mathrm{MHz}$, $\left.\mathrm{CDCl}_{3}\right): \delta 8.21$ (s, 2H, btd), 8.43 (s, 2H, 3-H-Tr), 9.80 (s, 2H, 5-H-Tr) ppm. ${ }^{13} \mathrm{C} \neg \mathrm{NMR}$ (125 MHz, $\mathrm{CDCl}_{3}$ ): $\delta 123.8$ (4,7-C-btd), 129.3 (5,6-C-btd), 141.4 (3-C-Tr), 150.4 (4a,7a-C-btd), 196.3 (5-C-Tr). NMR data (Figures S14 and S15) are consistent with the literature data [32].

\subsection{Synthesis of $\left[\mathrm{Zn}\left(\operatorname{tr}_{2} b t d\right)(b p d c)\right] \cdot D M F(\mathbf{1})$}

Total of $5 \mathrm{mg}(0.018 \mathrm{mmol})$ of $\operatorname{tr}_{2} \mathrm{btd}, 4.5 \mathrm{mg}(0.018 \mathrm{mmol})$ of biphenyl dicarboxylic acid, and $5.5 \mathrm{mg}(0.018 \mathrm{mmol})$ of zinc nitrate nitrate hexahydrate were dissolved in $1 \mathrm{~mL}$ of DMF:EtOH (3:1) mixed solvent with sonication and heated at $100{ }^{\circ} \mathrm{C}$ for $24 \mathrm{~h}$. Yellowgreenish needle crystals were filtered out, single crystals were picked out for the $\mathrm{X}$-ray analysis. Yield 78\%. $\mathrm{C}_{27} \mathrm{H}_{21} \mathrm{~N}_{9} \mathrm{O}_{5} \mathrm{SZn} \cdot 1.25 \mathrm{C}_{2} \mathrm{H}_{5} \mathrm{OH}$ (706.55): calcd. C 50.00; $\mathrm{H} 4.31$; N 17.85; S 4.54; found: C 49.6; H 3.5; N 17.9; S 4.7. FT-IR (cm $\left.{ }^{-1}\right)$ : $3500(\mathrm{~m}), 3000(\mathrm{~m}), 1656(\mathrm{~s})$, $1608(\mathrm{~s}), 1527(\mathrm{~s}), 1386(\mathrm{~s}), 1282(\mathrm{~m}), 1112(\mathrm{~s}), 983(\mathrm{~s}), 933(\mathrm{w}), 858(\mathrm{~s}), 773(\mathrm{~s}), 671(\mathrm{~s}), 615(\mathrm{w})$, $439(\mathrm{w})$.

\subsection{Luminescence Sensing Experiments}

Suspension of coordination polymer for screening test in DMA was prepared as follows: $10 \mathrm{mg}$ of $\mathbf{1}$ was carefully ground in mortar and then sonicated for $1 \mathrm{~h}$ in $10 \mathrm{~mL}$ of DMA and left standing for $24 \mathrm{~h}$. The supernatant (stable suspension) was separated and used in luminescence sensing experiments.

For the screening test, $250 \mu \mathrm{L}$ of suspension was diluted to $2 \mathrm{~mL}$ with fresh DMA and metal salt solution was added to achieve a concentration of $0.01 \mathrm{mM}$.

\subsection{Single Crystal X-ray Analysis}

Single crystal XRD data for 1 were collected with a Bruker D8 Venture diffractometer with a CMOS PHOTON III detector and I $\mu$ S 3.0 source (Mo K $\alpha$ radiation, $\lambda=0.71069 \AA$ ). All measurements were conducted at $150 \mathrm{~K}$, the $\varphi$ - and $\omega$-scan techniques were employed. Absorption corrections were applied with the use of the SADABS program [46].

The structure was solved by the direct methods and refined by the full-matrix least squares methods using SHELXT and SHELXL [47] with SHELXle GUI [48]. The nonhydrogen atoms were situated in successive difference Fourier syntheses and refined by anisotropic thermal parameters on F2. Hydrogen atoms were placed geometrically and treated as a mixture of independent and constrained refinement. The disordered electron density, which could not be satisfactorily modeled into solvent molecules was removed with the aid of PLATON SQUEEZE algorithm (electron count removed was 173, which corresponds to 3.76 molecules of EtOH per formula unit).

Crystal data for $\mathrm{C}_{27} \mathrm{H}_{21} \mathrm{~N}_{9} \mathrm{O}_{5} \mathrm{SZn}(M=648.98 \mathrm{~g} / \mathrm{mol})$ : monoclinic, space group $P 2_{1} / c$, $a=13.3256(3) \AA, b=13.3256(3) \AA, c=13.3256(3) \AA, \beta=104.9180(10)^{\circ}, V=8470.5(4) \AA^{3}$, $\mathrm{Z}=12, \mathrm{~T}=150(2) \mathrm{K}, \mu\left(\mathrm{MoK}_{\alpha}\right)=0.12 \mathrm{~mm}^{-1}, D_{\text {calc }}=1.527 \mathrm{~g} / \mathrm{cm}^{3}, 107669$ reflections measured, 26362 unique $\left(R_{\text {int }}=0.093, R_{\text {sigma }}=0.056\right)$. The final $R_{1}$ was $0.0563(\mathrm{I}>2 \sigma(\mathrm{I}))$, goodness of fit $\mathrm{S}$ was 1.027 and $w R_{2}$ was 0.141 (all data).

\section{Conclusions}

In summary, by exploiting the mixed-ligand design approach, a new 2D coordination polymer, which can be utilized as a "turn-on" fluorescence probe for the $\mathrm{Al}^{3+}$ in solution was prepared. The material obtained demonstrated suitable chemical stability and excellent sensitivity, selectivity for the presence of $\mathrm{Al}^{3+}$. The detection limit for $\mathrm{Al}^{3+}$ was among the lowest reported for the Al-sensitive coordination polymers. These results demonstrate the significance of a judicious ligand choice in the design of functional materials with desirable properties. 
Supplementary Materials: The following are available online, Figure S1. Hydrogen bonds between DMF molecules and 1,2,4-triazole fragments in the crystal structure of 1. Figure S2. Interlayer hydrogen bonds in the crystal structure of 1 . Figure S3. TGA curves of the coordination polymer 1. Figure S4. IR spectrum of the coordination polymer 1 in $\mathrm{KBr}$ pellet. Figure S5. Excitation and emission spectra of the $\mathrm{tr}_{2}$ btd ligand. Figure S6 Excitation and emission spectra of the $\mathrm{H}_{2}$ bpdc ligand. Figure S7. Fluorescence decay for 1 suspension in DMA. Figure S8. Fluoresce decay for 1 suspension in DMA in the presence of $\mathrm{Al}^{3+}$. Figure S9. Linear fit for higher concentration range of intensity-concentration correlation. Figure S10. Fluorescence intensity of 1 in sensor recycling experiments. Figure S11. Fluorescence intensity of 1 in experiments with real sample and spiking. Figure S12. Time-dependent emission spectra of 1 DMA suspension upon addition of $\mathrm{Al}^{3+}$. Figure S13. CIE 1931 chromaticity diagram with color coordinates for 1 and $1+\mathrm{Al}^{3+}$. Figure $\mathrm{S} 14 .{ }^{1} \mathrm{H} \mathrm{NMR}$ spectra of $\operatorname{tr}_{2}$ btd ligand in $\mathrm{CDCl}_{3}$ recorded at $500 \mathrm{MHz}$. Figure $\mathrm{S} 15 .{ }^{13} \mathrm{C}$ NMR spectra of $\operatorname{tr}_{2} \mathrm{btd}$ ligand in $\mathrm{CDCl}_{3}$ recorded at $125 \mathrm{MHz}$.

Author Contributions: Conceptualization, D.I.P. and A.S.P.; investigation, D.I.P. and A.A.R.; writingoriginal draft preparation, D.I.P.; writing-review and editing, A.S.P.; visualization, D.I.P. and A.A.R.; funding acquisition, A.S.P. All authors have read and agreed to the published version of the manuscript.

Funding: The reported study was funded by RFBR, project number 20-33-70026. NIIC analytical characterization facilities used in this work operate with support from the Ministry of Science and Higher Education of the Russian Federation, project numbers 121031700321-3 and 121031700313-8.

Institutional Review Board Statement: Not applicable.

Informed Consent Statement: Not applicable.

Data Availability Statement: CCDC 2121288 contains the supplementary crystallographic data for this paper. These data can be obtained free of charge from The Cambridge Crystallographic Data Center at http:/ / www.ccdc.cam.ac.uk/data_request/cif (accessed on 5 December 2021).

Acknowledgments: The authors thank XRD Facility of NIIC SB RAS for providing the single crystal diffraction data.

Conflicts of Interest: The authors declare no conflict of interest. The funders had no role in the design of the study; in the collection, analyses, or interpretation of data; in the writing of the manuscript, or in the decision to publish the results.

Sample Availability: Samples of the compounds $\operatorname{tr}_{2}$ btd and 1 are available from the authors.

\section{References}

1. Wu, X.; Cobbina, S.J.; Mao, G.; Xu, H.; Zhang, Z.; Yang, L. A review of toxicity and mechanisms of individual and mixtures of heavy metals in the environment. Environ. Sci. Pollut. Res. 2016, 23, 8244-8259. [CrossRef] [PubMed]

2. Scheuhammer, A.M. The chronic toxicity of aluminium, cadmium, mercury, and lead in birds: A review. Environ. Pollut. 1987, 46, 263-295. [CrossRef]

3. Tchounwou, P.B.; Yedjou, C.G.; Patlolla, A.K.; Sutton, D.J. Heavy metal toxicity and the environment. In Molecular, Clinical and Environmental Toxicology; Springer: Basel, Switzerland, 2012; Volume 101, pp. 133-164.

4. Valeur, B.; Leray, I. Design principles of fluorescent molecular sensors for cation recognition. Coord. Chem. Rev. 2000, 205, 3-40. [CrossRef]

5. Yokel, R.A. Aluminum reproductive toxicity: A summary and interpretation of scientific reports. Crit. Rev. Toxicol. 2020, 50, 551-593. [CrossRef] [PubMed]

6. Nieboer, E.; Gibson, B.L.; Oxman, A.D.; Kramer, J.R. Health effects of aluminum: A critical review with emphasis on aluminum in drinking water. Environ. Rev. 1995, 3, 29-81. [CrossRef]

7. Aydin, D. Sensing of aluminum and cyanide ions utilizing a novel bis-phenol a based fluorogenic probe: Applications in test stripts. Microchem. J. 2020, 159, 105477. [CrossRef]

8. D’Haese, P.C.; Douglas, G.; Verhulst, A.; Neven, E.; Behets, G.J.; Vervaet, B.A.; Finsterle, K.; Lürling, M.; Spears, B. Human health risk associated with the management of phosphorus in freshwaters using lanthanum and aluminium. Chemosphere 2019, 220, 286-299. [CrossRef] [PubMed]

9. Inan-Eroglu, E.; Ayaz, A. Is aluminum exposure a risk factor for neurological disorders? J. Res. Med. Sci. 2018, 23, 51. [PubMed]

10. Bondy, S.C. The neurotoxicity of environmental aluminum is still an issue. Neurotoxicology 2010, 31, 575-581. [CrossRef] [PubMed]

11. Bertsch, P.M.; Anderson, M.A. Speciation of Aluminum in Aqueous Solutions Using Ion Chromatography. Anal. Chem. 1989, 61, 535-539. [CrossRef] 
12. Di, J.; Bi, S.; Yang, T.; Zhang, M. Voltammetric determination of aluminum(III) using a reagentless sensor fabricated by sol-gel process. Sens. Actuators B Chem. 2004, 99, 468-473. [CrossRef]

13. LeGendre, G.R.; Alfrey, A.C. Measuring picogram amounts of aluminum in biological tissue by flameless atomic absorption analysis of a chelate. Clin. Chem. 1976, 22, 53-56. [CrossRef]

14. Quiñonero, J.; Mongay, C.; de la Guardia, M. Determination of aluminum at the parts per billion level by solvent extraction and flame atomic emission spectrometry. Microchem. J. 1991, 43, 213-221. [CrossRef]

15. Tian, J.; Yan, X.; Yang, H.; Tian, F. A novel turn-on Schiff-base fluorescent sensor for aluminum(III) ions in living cells. RSC Adv. 2015, 5, 107012-107019. [CrossRef]

16. Fu, J.; Yao, K.; Chang, Y.; Li, B.; Yang, L.; Xu, K. A novel colorimetric-fluorescent probe for $\mathrm{Al}^{3+}$ and the resultant complex for Fand its applications in cell imaging. Spectrochim. Acta-Part A Mol. Biomol. Spectrosc. 2019, 222, 117234. [CrossRef]

17. Li, Z.; Liu, C.; Wang, J.; Wang, S.; Xiao, L.; Jing, X. A selective diaminomaleonitrile-based dual channel emissive probe for $\mathrm{Al}^{3+}$ and its application in living cell imaging. Spectrochim. Acta Part A Mol. Biomol. Spectrosc. 2019, 212, 349-355. [CrossRef] [PubMed]

18. Alici, O.; Erdemir, S. A cyanobiphenyl containing fluorescence "turn on" sensor for $\mathrm{Al}^{3+}$ ion in $\mathrm{CH} 3 \mathrm{CN}$-water. Sens. Actuators $B$ Chem. 2015, 208, 159-163. [CrossRef]

19. Chen, C.H.; Liao, D.J.; Wan, C.F.; Wu, A.T. A turn-on and reversible Schiff base fluorescence sensor for $\mathrm{Al}^{3+}$ ion. Analyst 2013, 138, 2527-2530. [CrossRef]

20. Wang, Q.; Astruc, D. State of the Art and Prospects in Metal-Organic Framework (MOF)-Based and MOF-Derived Nanocatalysis. Chem. Rev. 2019, 120, 1438-1511. [CrossRef]

21. Goetjen, T.A.; Liu, J.; Wu, Y.; Sui, J.; Zhang, X.; Hupp, T.J.; Farha, O.K. Metal-organic framework (MOF) materials as polymerization catalysts: A review and recent advances. Chem. Commun. 2020, 56, 10409-10418. [CrossRef]

22. Li, X.; Liu, Y.; Wang, J.; Gascon, J.; Li, J.; Van der Bruggen, B. Metal-organic frameworks based membranes for liquid separation. Chem. Soc. Rev. 2017, 46, 7124-7144. [CrossRef] [PubMed]

23. Barsukova, M.O.; Kovalenko, K.A.; Nizovtsev, A.S.; Sapianik, A.A.; Samsonenko, D.G.; Dybtsev, D.N.; Fedin, V.P. Isomeric Scandium-Organic Frameworks with High Hydrolytic Stability and Selective Adsorption of Acetylene. Inorg. Chem. 2021, 60, 2996-3005. [CrossRef]

24. Sapianik, A.A.; Dudko, E.R.; Kovalenko, K.A.; Barsukova, M.O.; Samsonenko, D.G.; Dybtsev, D.N.; Fedin, V.P. Metal-Organic Frameworks for Highly Selective Separation of Xylene Isomers and Single-Crystal X-ray Study of Aromatic Guest-Host Inclusion Compounds. ACS Appl. Mater. Interfaces 2021, 13, 14768-14777. [CrossRef] [PubMed]

25. Kovalenko, K.A.; Potapov, A.S.; Fedin, V.P. Micro- and mesoporous metal-organic coordination polymers for separation of hydrocarbons. Russ. Chem. Rev. 2021, 90. [CrossRef]

26. Kuznetsova, A.; Matveevskaya, V.; Pavlov, D.; Yakunenkov, A.; Potapov, A. Coordination Polymers Based on Highly Emissive Ligands: Synthesis and Functional Properties. Materials 2020, 13, 2699. [CrossRef] [PubMed]

27. Wang, Y.; Zhang, X.; Zhao, Y.; Zhang, S.; Li, S.; Jia, L.; Du, L.; Zhao, Q. Three Novel Zn-Based Coordination Polymers: Synthesis, Structure, and Effective Detection of $\mathrm{Al}^{3+}$ and $\mathrm{S}^{2-}$ Ions. Molecules 2020, 25, 382. [CrossRef]

28. Guo, H.; Wu, N.; Xue, R.; Liu, H.; Li, L.; Wang, M.Y.; Yao, W.Q.; Li, Q.; Yang, W. Multifunctional Ln-MOF luminescent probe displaying superior capabilities for highly selective sensing of $\mathrm{Fe}^{3+}$ and $\mathrm{Al}^{3+}$ ions and nitrotoluene. Colloids Surf. A Physicochem. Eng. Asp. 2020, 585, 124094. [CrossRef]

29. Wang, Q.; Du, X.-M.; Zhao, B.; Pang, M.; Li, Y.; Ruan, W.-J. A luminescent MOF as a fluorescent sensor for the sequential detection of $\mathrm{Al}^{3+}$ and phenylpyruvic acid. New J. Chem. 2020, 44, 1307-1312. [CrossRef]

30. Zheng, X.; Zhao, Y.; Jia, P.; Wang, Q.; Liu, Y.; Bu, T.; Zhang, M.; Bai, F.; Wang, L. Dual-Emission Zr-MOF-Based Composite Material as a Fluorescence Turn-On Sensor for the Ultrasensitive Detection of $\mathrm{Al}^{3+}$. .Inorg. Chem. 2020, 59, 18205-18213. [CrossRef]

31. Chand, S.; Verma, G.; Pal, A.; Pal, S.C.; Ma, S.; Das, M.C. Porous Anionic Co(II) Metal-Organic Framework, with a High Density of Amino Groups, as a Superior Luminescent Sensor for Turn-on Al(III) Detection. Chemistry 2021, 27, 11804-11810. [CrossRef] [PubMed]

32. Qiu, C.Q.; Li, L.Q.; Yao, S.L.; Liu, S.J.; Xu, H.; Zheng, T.F. Two benzothiadiazole-based compounds as multifunctional fluorescent sensors for detection of organic amines and anions. Polyhedron 2021, 199, 115100. [CrossRef]

33. Blatov, V.A.; Shevchenko, A.P.; Proserpio, D.M. Applied topological analysis of crystal structures with the program package ToposPro. Cryst. Growth Des. 2014, 14, 3576-3586. [CrossRef]

34. Nakamoto, K. Infrared and Raman Spectra of Inorganic and Coordination Compounds, Part B. Applications in Coordination, Organometallic, and Bioinorganic Chemistry; Wiley-Interscience: Hoboken, NJ, USA, 2009.

35. Billes, F.; Endrédi, H.; Keresztury, G. Vibrational spectroscopy of triazoles and tetrazole. J. Mol. Struct. THEOCHEM 2000, 530, 183-200. [CrossRef]

36. Santra, A.; Francis, M.; Parshamoni, S.; Konar, S. Nanoporous Cu(I) Metal-Organic Framework: Selective Adsorption of Benzene and Luminescence Sensing of Nitroaromatics. ChemistrySelect 2017, 2, 3200-3206. [CrossRef]

37. Committee, A.M. Recommendations for the definition, estimation and use of the detection limit. Analyst 1987, 112, 199-204.

38. Yu, Y.; Wang, Y.; Yan, H.; Lu, J.; Liu, H.; Li, Y.; Wang, S.; Li, D.; Dou, J.; Yang, L.; et al. Multiresponsive Luminescent Sensitivities of a 3D Cd-CP with Visual Turn-on and Ratiometric Sensing toward $\mathrm{Al}^{3+}$ and $\mathrm{Cr}^{3+}$ as Well as Turn-off Sensing toward Fe ${ }^{3+}$. Inorg. Chem. 2020, 59, 3828-3837. [CrossRef] 
39. Yuan, G.; Zhang, C.; Xu, D.J.; Shao, K.Z.; Li, X.M.; Hao, X.R.; Su, Z.M. A water-stable Tb(III) coordination polymer based on 2-(4-carboxyphenyl)-1H-imidazole-4,5-dicarboxylic acid: Synthesis, structure, color-tunable fluorescence and sensing properties. Inorg. Chem. Commun. 2021, 125, 108458. [CrossRef]

40. Tsai, M.J.; Liao, K.S.; Hsu, L.J.; Wu, J.Y. A luminescent Cd(II) coordination polymer as a fluorescence-responsive sensor for enhancement sensing of $\mathrm{Al}^{3+}$ and $\mathrm{Cr}^{3+}$ ions and quenching detection of chromium(VI) oxyanions. J. Solid State Chem. 2021, 304, 122564. [CrossRef]

41. Zhang, X.; Luo, X.; Zhang, N.; Wu, J.; Huang, Y.Q. A highly selective and sensitive Zn(II) coordination polymer luminescent sensor for Al3+ and NACs in the aqueous phase. Inorg. Chem. Front. 2017, 4, 1888-1894. [CrossRef]

42. Li, C.; Li, X.Y.; Han, S.D.; Pan, J.; Li, J.H.; Wang, G.M. Luminescent Turn-On/Turn-Off Sensing Properties of a Water-Stable Cobalt-Based Coordination Polymer. Cryst. Growth Des. 2021, 21, 2332-2339. [CrossRef]

43. Tian, X.M.; Yao, S.L.; Qiu, C.Q.; Zheng, T.F.; Chen, Y.Q.; Huang, H.; Chen, J.L.; Liu, S.J.; Wen, H.R. Turn-On Luminescent Sensor toward $\mathrm{Fe}^{3+}, \mathrm{Cr}^{3+}$, and $\mathrm{Al}^{3+}$ Based on a $\mathrm{Co}(\mathrm{II})$ Metal-Organic Framework with Open Functional Sites. Inorg. Chem. 2020, 59, 2803-2810. [CrossRef] [PubMed]

44. Yao, S.L.; Xiong, Y.C.; Tian, X.M.; Liu, S.J.; Xu, H.; Zheng, T.F.; Chen, J.L.; Wen, H.R. A multifunctional benzothiadiazole-based fluorescence sensor for $\mathrm{Al}^{3+}, \mathrm{Cr}^{3+}$ and $\mathrm{Fe}^{3+}$. CrystEngComm 2021, 23, 1898-1905. [CrossRef]

45. Yao, S.L.; Tian, X.M.; Li, L.Q.; Liu, S.J.; Zheng, T.F.; Chen, Y.Q.; Zhang, D.S.; Chen, J.L.; Wen, H.R.; Hu, T.L. A CdII-Based Metal-Organic Framework with pcu Topology as Turn-On Fluorescent Sensor for Al ${ }^{3+}$. Chem.-Asian J. 2019, 14, 3648-3654. [CrossRef] [PubMed]

46. APEX2 (Version 2.0), SAINT (Version 8.18c), and SADABS (Version 2.11), Bruker Advanced X-ray Solutions; Bruker AXS Inc.: Madison, WI, USA, 2000.

47. Sheldrick, G.M. SHELXT-Integrated space-group and crystal-structure determination. Acta Crystallogr. Sect. A 2015, 71, 3-8. [CrossRef] [PubMed]

48. Sheldrick, G.M. Crystal structure refinement with SHELXL. Acta Crystallogr. Sect. C 2015, 71, 3-8. [CrossRef] [PubMed] 